\title{
Predictors of colony extinction vary by habitat type in social spiders
}

\author{
Brendan L. McEwen ${ }^{1}$, James L. L. Lichtenstein ${ }^{2}$, David N. Fisher ${ }^{1}$, Colin M. Wright ${ }^{3}$, Greg T. \\ Chism $^{4}$, Noa Pinter-Wollman ${ }^{5}$, Jonathan N. Pruitt ${ }^{1,2}$ \\ ${ }^{1}$ Department of Psychology, Neuroscience \& Behaviour, McMaster University, Hamilton, Ontario \\ L8S 4K1, Canada \\ 2Department of Ecology, Evolution \& Marine Biology, University of California at Santa Barbara, \\ Santa Barbara, CA 93106, USA \\ ${ }^{3}$ Department of Biology, Pennsylvania State University, University Park, PA 16801, USA \\ ${ }^{4}$ Graduate Student Interdisciplinary Program in Entomology \& Insect Science, University of \\ Arizona, Tucson, AZ 85721, USA \\ ${ }^{5}$ Department of Ecology \& Evolutionary Biology, University of California - Los Angeles, Los \\ Angeles, CA 90095, USA
}

\section{Abstract}

Many animal societies are susceptible to mass mortality events and collapse. Elucidating how environmental pressures determine patterns of collapse is important for understanding how such societies function and evolve. Using the social spider Stegodyphus dumicola, we investigated the environmental drivers of colony extinction along two precipitation gradients across southern Africa, using the Namib and Kalahari deserts versus wetter savanna habitats to the north and east. We deployed experimental colonies $(n=242)$ along two $\sim 800-\mathrm{km}$ transects and returned to assess colony success in the field after 2 months. Specifically, we noted colony extinction events after the 2-month duration and collected environmental data on the correlates of those extinction events (e.g., evidence of ant attacks, no. of prey captured). We found that colony extinction events at desert sites were more frequently associated with attacks by predatory ants as compared with savanna sites, while colony extinctions in wetter savannas sites were more tightly associated with fungal outbreaks. Our findings support the hypothesis that environments vary in the selection pressures that they impose on social organisms, which may explain why different social phenotypes are often favored in each habitat.

\footnotetext{
Brendan L. McEwen, Mceweb1@ mcmaster.ca.

Author contributions JNP and NPW conceived the experiment. BLM, JLL, CMW, GTC, and JNP performed the experiment. BLM and DNF analyzed the data. BLM, DNF, and JNP wrote the manuscript; other authors provided editorial input.

Electronic supplementary material The online version of this article (https://doi.org/10.1007/s00265-019-2781-x) contains supplementary material, which is available to authorized users.

Data availability Data will be made available at request to authors BLM or JNP.

Compliance with ethical standards

Conflict of interest The authors declare that they have no conflict of interest.

Publisher's note Springer Nature remains neutral with regard to jurisdictional claims in published maps and institutional affiliations.
} 


\section{Keywords}

Colony collapse; Disease; Extinction; Geographic variation; Local adaptation

\section{Introduction}

The evolution of sociality changes the ways in which species interact with their environments. Living in groups can confer the ability to construct larger refuges, subdue more profitable prey, mount amplified defenses against would-be enemies, and increase fitness through alloparental care (Krause \& Ruxton 2002, Lubin \& Bilde 2007). However, sociality is not without costs. Group-living organisms may suffer enhanced resource competition as they struggle to support a larger number of co-occurring conspecifics (Yip et al. 2008, Mayer et al. 2018). They may become more conspicuous to predators (Wrona \& Dixon 1991) or be more susceptible to disease (Côté \& Poulinb 1995). These costs can accumulate to a critical level at which they outweigh the benefits conferred by sociality, causing a group to collapse or go extinct (Avilés and Tufino 1998).

Site-specific selection, through which discrete areas impose divergent selection on a species, is a relatively common feature in nature that often results in phenotypic diversity (Siepielski et al. 2009, Siepielski et al. 2013, Caruso et al. 2017). For example, spatial and temporal variation in precipitation patterns (Siepielski et al. 2017), prey community structure (Drummond \& Burghardt 1983), or interference competition (Riechert 1993) can all generate contrasting patterns of selection on individuals, often resulting in local adaptation. We propose that, like selection pressures predicting the survival or demise of individuals, pressures driving group extinction events might differ according to the environments in which a group resides.

Social spiders provide a convenient means with which to observe the relationship between the environment and group extinctions. Most species of spider are solitary and intolerant of conspecifics; however, social species are less aggressive overall and have higher conspecific tolerance than their solitary counterparts (Lubin \& Bilde 2007, Harwood \& Avilés 2018). This distinction allows social spiders to coexist in a communal web and work cooperatively on collective tasks, such as foraging (Whitehouse \& Lubin 2005), web construction and maintenance (Riechert 1985, Purcell \& Avilés 2008), alloparental care (Whitehouse \& Jackson 1998), and defense against predator attacks (Henschel 1998, Purcell \& Avilés 2008, Yip \& Rayor 2011, Wright et al. 2016). Despite these seemingly adaptive collective behaviors, however, many species of social spiders experience high rates of colony extinction in the wild (Aviles 1986, Henschel 1998).

Several hypotheses have been proposed to explain the high incidence of colony extinction events in social spiders. First, the transition to sociality in spiders is met with a transition from outbreeding to inbreeding, which results in low effective population sizes and a reduced ability to response to changing environmental pressures (Agnarsson et al. 2006, Settepani et al. 2017). Second, the evolution of sociality is associated with a decrease in cross-contextual aggressiveness (e.g., towards conspecifics, heterospecifics, prey, and potential predators/parasites) and increased conspecific densities that together render social 
spiders susceptible to a diversity of ecological pressures (Pruitt et al. 2012). These pressures include invasion by foreign species of spiders (Cangialosi 1990, Pruitt 2012), increased detection rate by ant predators (Purcell \& Aviles 2008, Keiser et al. 2015), increased susceptibility to starvation and local resource competition (Aviles et al. 2002, Yip et al. 2008, Majer et al. 2018), and an increased propensity to spread socially transmitted microbes (Henschel 1998, Keiser et al. 2018). Different habitats may vary in the severity of these pressures based on local conditions (e.g., prey availability, predator abundance).

In this study, we evaluate whether environments with contrasting precipitation regimes differ in the factors associated with group extinction events. Precipitation has been identified as a key driver of selection across many systems (Purcell 2011, Hoffman \& Avilés 2017, Siepielski et al. 2017) and, as we outline below, is a candidate variable that may influence the threats to the survival of social spider groups.

The social spider Stegodyphus dumicola (Araneae, Eresidae) occupies both arid and wet regions throughout southwestern Africa in colonies ranging from 1 to 2000 spiders (reviewed in Avilés \& Guevara 2017). Stegodyphus dumicola colonies in the wild experience mixed success. Though the species is reasonably common, $S$. dumicola experiences high colony extinction rates (Henschel 1998, Pruitt et al. 2018; data herein). The causes of these high mortality rates are potentially manifold, such as a failure to capture sufficient prey (Majer et al. 2018), succumbing to colony attacks performed by ants (Henschel 1998, Keiser et al. 2015), and the spread of fungus through the colony web (Henschel 1998). The high rate of colony extinction in $S$. dumicola renders this species as a convenient model with which to explore associations between habitat type and the correlates of colony extinction. Prior studies on $S$. dumicola have found that the relationship between colony traits and success differs predictably across wet vs. arid sites (Pruitt et al. 2018), hinting that the pressures driving colony success and collapse may differ across environments.

Here we evaluate the following a priori predictions: we predict that colonies at wet savanna sites will capture more prey than colonies at arid sites, because insect abundance and biomass increase in habitats with higher precipitation (Janzen and Schoener, 1968). However, increased insect prey parts within spider webs combined with higher moisture at wet sites may facilitate the growth of fungus. Thus, we predict colony extinctions will be more frequently associated with fungal outbreaks at wet sites than at arid sites. Prior studies at arid sites have demonstrated that predatory ants are a lethal and disruptive force upon $S$. dumicola (Henschel 1998, Keiser et al. 2015, Wright et al. 2017). Although the threat of predatory ants towards $S$. dumicola has not been directly assessed in wet habitats, increased ant abundance in habitats with greater primary productivity suggests that these pressures may be even stronger at wet sites (Kaspari et al. 2000). Accordingly, we predict that higher ant populations at wet sites will increase frequency of attacks by predatory ants, as well as colony mortalities due to ant attack. To evaluate these predictions, we compared the frequency of colony extinction events between desert and savanna sites and evaluated whether the factors associated with colony extinction differed predictably across these habitat types. 


\section{Methods}

The data herein were collected as part of a larger study examining site-specific selection on collective behavior and leader-follower interactions in social spiders (Pruitt et al. 2018). Pruitt et al. (2018) evaluated for and confirmed the presence of site-specific selection for social susceptibility at arid sites, using the survivorship data presented in this paper along with behavioral data not used here. The following data on correlates of extinction and risk of various selective agents, which are the unique focus of this paper, have not been published previously. The current paper therefore aims to identify differences in environmental selective forces that may underlie the site-specific selection described in Pruitt et al. (2018). There are no redundant conclusions between this paper and any other work published by our group.

All applicable institutional and/or national guidelines for the care and use of animals were followed.

\section{Collection}

We collected whole colonies of $S$. dumicola along roadside fences and Senegalia mellifera trees at eight study sites. Sites were distributed across two precipitation transects: one extending north from the Namib Desert towards Angola $(810 \mathrm{~km})$, the other extending east from the Kalahari Desert towards Lesotho $(981 \mathrm{~km}$ ) (Fig S1). Each transect contained four sites, two arid desert sites (Kalahari gradient: Upington [- 28.403361, 21.071249] and Boegoeberg [- 29.037819, 22.027999]; Namib gradient: Rehoboth [- 23.209881, 17.092] and Kalkrand [-24.065027, 17.580452]) and two wetter savanna sites (Kalahari gradient: Ladysmith [- 38.65655, 29.625249] and Weenen [ - 28.856239, 30.142306]; Namib gradient: Rundu [- 18.299209, 19.407636] and Outjo [- 20.233099, 16.354468]). In all, we collected 211 source colonies with populations of mature females spanning from 75 to 512 individuals per colony.

We collected colonies by placing a cloth pillowcase over the entire nest, then either prying the nest loose from fence wires or using garden clippers to separate the retreat from its substrate. We transported colonies in a climate-controlled vehicle to nearby hotels for separation/isolation. We individually dissected colonies by hand, separating each mature female spider into a 59-ml deli cup for a $24-\mathrm{h}$ isolation period prior to assembling experimental colonies. When creating experimental groups, care was taken not mix individuals from multiple source colonies. In social Stegodyphus, variation in relatedness and/or familiarity has been demonstrated to alter colony behavior and performance (Modlmeier et al. 2014, Laskowski et al. 2016).

\section{Experimental colony assembly}

We created a total of 242 experimental colonies, each containing 20 mature female spiders. Experimental colonies were housed in 390-ml plastic cups, each containing three $S$. mellifera twigs to facilitate web construction. Several holes were punched into the bottom of each cup to allow for water drainage for instances of rain. Colonies were housed in their group cups for a total of 5 days at a temperature of $22-25{ }^{\circ} \mathrm{C}$ before deployment into the 
field at their respective sites. During this time, colonies were able to acclimate to their new housing as well as build a silken retreat structure. This serves to both disincentivize dispersal from their deployment location and provide structural protection from their environment during colony establishment.

\section{Experimental colony deployment}

We deployed our experimental colonies across the eight sites (28-33 colonies per site) using clothespins to attach individual cups to $S$. mellifera trees. Each colony was attached to its own tree (> 3-m distance between deployment trees) to minimize interaction between colonies. Stegodyphus dumicola individuals will occasionally disperse to the nearest branch tip following deployment, but most frequently begin building their capture web directly atop the clothespin fixing their cup to the substrate. Allowing a pre-deployment period for the spiders to weave and establish a retreat structure serves to suppress post-deployment dispersion and has been successfully implemented in prior field experiments using experimental colonies of $S$. dumicola (Grinsted et al. 2013, Keiser \& Pruitt 2014, Keiser et al. 2015, Wright et al. 2017). Colonies were not deployed onto trees that were actively being patrolled by predatory ants (genera Anoplolepis and Crematogaster), as these ants have previously been demonstrated to destroy colonies before they can become established (Keiser et al. 2015) and actively rove vegetation in search of prey (Doering et al. 2018). Colonies were deployed in an order that did not conflate one climate type with time of release: (1) wet (Rundu, Nov 2016), (2) wet (Outjo, Nov 2016), (3) dry (Rehoboth, Nov 2016), (4) dry (Kalkrand, Nov 2016), (5) dry (Upington, Dec 2016), (6) dry (Boegoeberg, Dec 2016), (7) wet (Ladysmith, Dec 2016), (8) wet (Weenen, Jan 2017). Colonies were deployed at the same site from which their source colonies were collected.

\section{Colony checks and correlates of extinction}

To determine colony survival, colonies were left in their environments for the next 2 months. We then returned to each colony and determined whether it had survived or had gone extinct. We deemed a colony to have gone extinct if no living members of the society persisted.

To determine the potential causes of colony extinction, in addition to evaluating survival, we noted cues as to whether both surviving and extinct colonies had experienced attack by predatory ants or fungal outbreak. Substantial quantities of Anoplolepis spp. ant carcasses in the capture web, nest, and deployment container provided evidence of an attack by ants (Yip \& Rayor 2011, Keiser et al. 2015). Stedodyphus dumicola do not generally consume Anoplolepis as prey, and instead respond in an antipredator fashion by weaving hyperadhesive cribellate silk to stave ants off from the retreat (Henschel 1998, Keiser et al. 2015). Evidence of a fungal outbreak was noted if fungus was sprouting from carcasses of colony members, prey items, and the web (Henschel 1998). To measure the amount of prey captured by the colony, we recorded the number of desiccated prey carcasses within each capture web and nest. Unlike many spider species that discard prey carcasses from their web after consumption, $S$. dumicola instead weave spent prey items directly into the threedimensional retreat structure of their web. As such, an observer may count the number of prey items captured by the colony. 


\section{Statistical methods}

We first established that our arid and wet sites experienced quantitatively different rates of precipitation by performing a $t$ test on each site's monthly rainfalls over the 5 years preceding the experiment (2013-2017). We grouped Kalkrand (Namibia), Rehoboth (Namibia), Upington (S. Africa), and Boegoeberg (S. Africa) as our arid sites, and grouped Rundu (Namibia), Outjo (Namibia), Ladysmith (S. Africa), and Weenen (S. Africa) as our wet sites. Rainfall data specific to these sites was obtained from World Weather Online.

We used GLMMs to test for associations between colony persistence, factors reasoned to cause colony extinctions in $S$. dumicola (ant attacks, fungal outbreak, no. of prey captured), and habitat type (arid/wet) in R (RStudio ver. 1.1.383) using the package lme4 (Bates et al. 2014). We first compared overall rates of colony extinction between arid and wet sites by constructing a model with site type (arid/wet) as a fixed effect, site ID as a random effect, and colony survival (1/0) as a binary response variable. We used a binomial error distribution with a logit-link function.

To investigate how site type affected prey capture rates, we constructed a model including site type (arid/wet) as a fixed effect, site ID as a random effect, and the number of prey recovered from the colony's web as a response variable. We fitted a Poisson error distribution and log-link function. This model included data only from colonies that both survived the duration of our study and were not attacked by ants. This is because (i) colonies that perished would have had different and unknown lengths of time in which to capture prey and (ii) ants typically steal prey during attacks on $S$. dumicola, thus obscuring prey capture estimates from those colonies (Henschel 1998).

To test for an association between mortality due to fungal outbreak and site type, we constructed a model with site type as a fixed effect, and site ID as a random effect, and incidence of fungal outbreak (1/0) as a binary response variable. We designated a binomial error distribution with a logit-link function. To focus on mortality-specific incidences of fungal outbreak, this model included data only from colonies that perished.

To test whether ant attacks occurred more frequently at wet sites, we constructed a model with site type as a fixed effect, site ID as a random effect, and evidence of ant attack (1/0) as a binary response. We designated a binomial error distribution with a logit-link function. We included both surviving and extinct colonies in this analysis; including both fatal and nonfatal attack events informs us of the overall frequency of predatory ant encounters. To evaluate whether colony mortality due to ant attack was more prevalent at wet sites, we constructed a model including site type as a fixed effect, site ID as a random effect, and evidence of ant attack as a binary response variable (1/0). We designated a binomial error distribution with a logit-link function. For this model, we used data only from colonies that had perished in order to focus on mortality-specific instances of these attacks.

In a post hoc analysis, we tested whether the number of prey present in a web was associated with fungal outbreaks. For this model, we ran a GLMM with prey number, site type, and their interaction term as fixed effects, site ID as a random effect, and incidence of fungal outbreak as a binary response. 


\section{Results}

As predicted, we found that our arid and wet site designations reflected quantitatively different precipitation regimes. Monthly precipitation at wet sites was found to be higher than that at arid sites $(t=6.12, p<0.0001)$. Notably, wet sites experienced over double $(\sim 45$ $\mathrm{mm}$ per month) the rainfall of arid sites ( $22 \mathrm{~mm}$ per month) during their rainy season of December through March.

We found that colonies at arid and wet sites experienced comparable survival rates ( 55\% arid vs. $\sim 44 \%$ wet), with a non-significant trend towards colonies surviving slightly better at arid sites ( site type: $z$-stat $=-1.787$, df.resid $=239, p=0.0739$ ).

Among surviving groups that had not been raided by ants ( 47 colonies or $41 \%$ of colonies at arid sites; 48 colonies or $38 \%$ of colonies at wet sites, Table 1), colonies at wet sites had higher prey capture rates than colonies at dry sites ( site type: $z$-stat $=8.853$, df.resid $=94, p$ $<0.0001$; Fig. 1). Surviving colonies at wet sites contained an average of 10.3 prey items, whereas colonies at arid sites contained an average of 5.2 prey items (Table 1).

Our prediction that fungal outbreaks would be associated with colony extinctions at wet sites was corroborated by our data. A total of 31 colonies ( 5 colonies or $4 \%$ of deployed colonies at arid sites; 26 colonies or $21 \%$ of deployed colonies at wet sites, Table 1) displayed evidence of fungal outbreak. Only 6 of these colonies survived the duration of the study. Among colonies that perished, we detected a significant difference in the frequency of fungal outbreaks across site types ( site type: $z$-stat $=3.248$, df.resid $=120, p=0.0012$; Fig. 2). Evidence of fungal outbreak was observed in $32 \%$ of the colonies that perished at wet sites and only $4 \%$ of colonies that perished at arid sites (Table 1).

We found that prey capture rates were positively associated with fungus across both site types, as the fixed effect of prey number was significant (prey number: $z$-stat $=2.367$, df.resid $=237, p=0.01795$; Fig. 3 ) but the interaction term was not (site type $x$ prey number: $p=0.0957)$. Therefore, colonies that had a greater number of prey carcasses in the web were more likely to experience fungal outbreaks, regard-less of site type (Fig. 3).

Our prediction that frequency of ant attack would be higher at wet sites was not corroborated by our data. Instead, the frequency of ant attack (including all attack events, survived by the colony or not) was higher in arid habitats than in wet habitats ( site type: $z$-stat $=-3.630$, df.resid $=239, p=0.0003$ ). A total of 67 (45 colonies or 39\% of deployed colonies at arid sites; 22 colonies or $17 \%$ of deployed colonies at wet sites, Table 1) colonies had evidence of ant attack, 45 of which went extinct. Among colonies that perished, we found that the arid site type was associated with evidence of ant attacks ( site type: $z$-stat $=-4.027$, df.resid $=$ $120, p<0.0001$; Fig. 2). At arid sites, 58\% of colony extinction events were associated with evidence of attacks by ants. In contrast, at wet sites, only $21 \%$ of colony mortality events were associated with evidence of an attack by ants (Table 1 ).

Of the 67 colonies that displayed signs of an ant attack, only 2 colonies had any prey items remaining in their web. Both prey-containing webs yielded only one prey item each: the elytra of a very large beetle. This result is consistent with prior field observations that 
Anoplolepis ants will consume $S$. dumicola, nest webbing, and remnant prey carcasses during attacks (Henschel 1998).

\section{Discussion}

The study herein leverages a large array of experimental colonies distributed across two deserts and their associated savannahs to evaluate possible drivers of colony extinctions in social spiders. While these data are admittedly only correlative and of a coarse temporal sampling scheme, we detected highly reliable associations between habitat type and likely drivers of colony extinction. We found that ant attacks were the most common correlate of colony extinction events at arid sites, whereas fungal outbreaks were most commonly associated with colony extinction events at wetter savannas. These differences may therefore impose divergent selection pressures on colony attributes at different site types, as has previously been shown in $S$. dumicola (Pruitt et al. 2018), the Amazonian social spider Anelosimus eximius (Lichtenstein et al. 2019), and the transitionally social spider Anelosimus studiosus (Pruitt \& Goodnight 2014).

We did not observe clear differences in overall survivorship/extinction rates in colonies across arid versus wet sites. Thus, both kinds of environments appear equally lethal to colonies, but sources of mortality differ. Colonies were deemed extinct if they contained no living members upon final evaluation. It is admittedly possible that some colonies were misclassified as extinct, if all living members dispersed before evaluation. However, multiple assessments were taken during colony deployment to verify that our experimental colonies were appropriately settled. Furthermore, for colonies that perished in association with fungal outbreaks, the carcasses of the spiders were still clearly visible in the ruined nest. This too conveys that these "extinctions" were not merely mass dispersal events that varied by site or habitat type. Finally, there is no evidence that long-distance dispersal from our colonies either is common or varies between arid and wet sites. We therefore reason that our assessments of colony extinctions are consistent across our two site types and represent legitimate colony-wide extinctions.

Our first prediction posited that colonies in wet sites would capture more prey than colonies in arid sites. When examining only surviving colonies, which had equal amounts of time to capture prey, we found that colonies in wet sites indeed had capture rates approximately twice those of colonies at arid sites. This is consistent with data demonstrating that savannas are more productive habitats than tropical deserts (Lieth 1973) and support larger numbers of phytophagous insects (Janzen and Schoener, 1968), which constitute most of the prey for S. dumicola (Majer et al. 2018). Prey size was not directly recorded in our observations. However, wetter habitats are generally home to a higher number of smaller, soft-bodied insects compared with deserts, where desiccation risk is more pronounced (Loveridge 1968, Edney 2012). This could skew average prey size across our site types, such that colonies at wet sites might capture smaller prey on average. However, these soft-bodied prey items are not predicted to leave behind as many conspicuous chitinous remains (more characteristic of larger insects), which we used as evidence for prey capture success. Thus, we would predict that our assessment strategy would have underestimated the prey captured by colonies at wet 
sites relative to arid sites. Yet, we still observed far more prey captured by the webs of colonies at wet sites relative to arid sites.

Consistent with predictions, fungal outbreaks were both more frequent and more commonly associated with extinction in wet sites than in arid sites. One of the likely causes of these outcomes is that entomopathogenic fungus may require more humid conditions to persist and reproduce. This humidity may interact with the higher number of prey items in webs at wet sites to increase the chance of unconsumed prey spoiling and sprouting fungus. Wet sites may also have greater prey diversity with the potential to harbor and transmit fungus to $S$. dumicola colonies. Colonies at wet sites have a higher interaction rate with such prey, as evidenced by their incorporating a larger number of prey carcasses into their webs. Each of these factors has the potential to contribute to increased fungal outbreaks observed at wet sites. Recent metagenomic data from the webs, nests, and cuticles of $S$. dumicola confirm that microbial transmission from prey to spiders is common (Keiser et al. 2019). Furthermore, prior observations of $S$. dumicola colonies infected by fungus note that individuals "became lethargic and died" (Henschel 1998), indicating that fungal infection can lead to the mortality of these spiders. Alternatively, it is also possible that fungal outbreaks may occur after a colony's demise. This would give the appearance that a colony had been killed by a fungal outbreak. However, the fact that several colonies were observed to be infected by fungus and still functional lends support to the hypothesis that fungal outbreak precedes colony extinction. Further, were fungal outbreaks merely a byproduct of extinct colonies rotting in a wetter environment, the relationship between increased prey capture and fungal outbreak might have been weaker or non-existent altogether.

At odds with our primary predictions, ant attacks appeared to be both more frequent at arid sites and more likely to lead to mortality for arid-dwelling colonies. Whether ants that prey upon $S$. dumicola are indeed more abundant at arid sites is yet unclear. We reason that an identical number of predatory ants at arid sites could prove more lethal to social spiders than the same number of ants at wet sites. This is because arid deserts, being less structurally complex than wetter savannas, are potentially easier for predatory ants to navigate and explore, leaving little opportunity for social spider colonies to go unnoticed. It is also likely that there are fewer alternative prey at arid sites that might distract predatory ants or satiate them. Deserts are known to limit the time and number of days that ant colonies can forage (Gordon 1991, Pinter-Wollman et al. 2012, Gordon 2013) and their prey preferences (Traniello et al. 1984), due to worker desiccation risk. If this is true in Anoplolepis, then this imposition is insufficient to decrease ant-driven lethality to social spider colonies at these sites.

We found that most of the spider colonies attacked by ants had zero prey items in their web. Of the 67 colonies that displayed signs of ant attack, only 2 colonies had prey in their capture webs. Observations of interactions between Anoplolepis ants and S. dumicola note that attacking ants eat nearly everything in the capture web during their attack (Henschel 1998, Keiser et al. 2015). Additionally, should a colony survive an ant attack (as in 22 of 67 observed attacks in this study), a history of ant attacks is known to decrease colony foraging aggressiveness (Wright et al. 2017). Thus, even non-lethal attacks by ants, if suffered early enough in a colony's history, could render the group less likely to capture prey later. This 
could also contribute to the observed differences in prey capture rates across sites, because colonies at arid sites captured fewer prey. These effects are costly, as collective foraging aggressiveness is associated with colony mass gain and colony persistence in this system (Pinter-Wollman et al. 2017, Pruitt et al. 2018, Kamath et al. 2018a).

Roughly $30 \%$ of extinctions in arid sites and $40 \%$ of extinctions in wet sites did not display evidence of ant attack or fungal outbreak, demonstrating that there are other factors influencing colony mortality. Prior work over a smaller spatial scale (Henschel et al. 1996, Henschel 1998) more exhaustively documents the various agents of mortality in S. dumicola. Potential sources of our undiagnosed extinctions are numerous but include biotic factors such as predatory birds, wasps (Rayor \& Uetz 1990, Rayor 1996), and kleptoparasitic or araneophagous spiders (Cangialosi 1990, Rypstra \& Tirey 1991), as well as abiotic factors (e.g., stochastic damage to the deployment tree). However, prior work on S. dumicola (Henschel 1996) identified predatory ants and fungal outbreaks as the most potent agents of colony extinctions in this system (e.g., predation by ants accounting for $45 \%$ of mortalities, compared with predation by birds and araneophagous spiders at $3 \%$ each and predation by wasps at $1 \%$ ), which served as motivation for our focusing on these sources of mortality.

Identifying spatial (between environments) and temporal (between seasons and across years; as in Bengston 2018) variation in selection on collective phenotypes helps us to understand the context-dependent evolution of these traits (Wray et al. 2011, Scharf et al. 2012, Bengston \& Dornhaus 2014, Jandt et al. 2014, Jolles et al. 2018, Kamath et al. 2018b). In a prior study, Pruitt et al. (2018) demonstrated the existence of site-specific selection on colony aggression in $S$. dumicola. In this study, we delved further into this system to test for environmental correlates of these extinction events to ascertain what factors might cause site-specific selection on colony behavior. We found that the correlates of colony extinction differed characteristically across site types in $S$. dumicola, with ant attacks being associated with colony extinction primarily at arid sites and fungal outbreaks being associated with extinctions at wet sites. These differences, in turn, may help to explain the differences in selection pressures on colony behavior seen in S. dumicola (Pruitt et al. 2018). While we reason that similar site specificity of group extinction drivers could be common in other social taxa, more field data like the kind herein are required to critically evaluate the generality of such findings.

\section{Supplementary Material}

Refer to Web version on PubMed Central for supplementary material.

\section{Acknowledgments}

Special thanks are due to Ian Van Wert, for keeping science cool. We would also like to thank several anonymous reviewers for their input which considerably improved the manuscript.

Funding information Funding was provided by NSF IOS grants 1352705 and 1455895 to JNP and 1456010 to NPW and NIH grant GM115509 to NPW and JNP. 


\section{References}

Agnarsson I, Avilés L, Coddington JA, Maddison WP (2006) Sociality in theridiid spiders: repeated origins of an evolutionary dead end. Evolution 60:2342-2351. 10.1111/j.0014-3820.2006.tb01869.x [PubMed: 17236425]

Aviles L (1986) Sex-ratio bias and possible group selection in the social spider Anelosimus eximius. Am Nat 128:1-12. 10.1086/284535

Aviles L, Abbot P, Cutter AD (2002) Population ecology, nonlinear dynamics, and social evolution. I. Associations among nonrelatives. Am Nat 159:115-127. 10.1086/324792 [PubMed: 18707408]

Avilés L, \& Guevara J (2017). Sociality in spiders. Rubenstein D, Abbot P (Cambridge Univ Press, Cambridge, UK), 188-223

Avilés L, Tufino P (1998) Colony size and individual fitness in the social spider Anelosimus eximius. Am Nat 152:403-418. 10.1086/286178 [PubMed: 18811448]

Bates D, Maechler M, Bolker B, \& Walker S (2014). lme4: linear mixed-effects models using Eigen and S4. R package version 1: 1-23

Bengston SE, Dornhaus A (2014) Be meek or be bold? A colony-level behavioural syndrome in ants. Proc Royal Soc Lond B 281: 20140518 10.1098/rspb.2014.0518

Bengston SE (2018) Life-history and behavioral trait covariation across 3 years in Temnothorax ants. Behav Ecol 29:1494-1501. 10.1093/beheco/ary101

Caruso CM, Martin RA, Sletvold N, Morrissey MB, Wade MJ, Augustine KE, Carlson SM, MacColl A, Siepielski AM, Kingsolver JG (2017) What are the environmental determinants of phenotypic selection? A meta-analysis of experimental studies. Am Nat 190:363-376. 10.1086/692760 [PubMed: 28829646]

Cangialosi KR (1990) Social spider defense against kleptoparasitism. Behav Ecol Sociobiol 27:49-54. 10.1007/BF00183313

Côté IM, Poulinb R (1995) Parasitism and group size in social animals: a meta-analysis. Behav Ecol 6:159-165. 10.1093/beheco/6.2.159

Doering GN, Kamath A, Wright CM, Pruitt JN (2018) Evidence for contrasting size-frequency distributions of workers patrolling vegetation vs. the ground in the polymorphic African ant Anoplolepis custodiens. Insect Soc 65:663-668. 10.1007/s00040-018-0645-4

Drummond H, Burghardt GM (1983) Geographic variation in the foraging behavior of the garter snake, Thamnophis elegans. Behavl Ecol Sociobiol 12:43-48. 10.1007/BF00296931

Edney EB (2012). Water balance in land arthropods (Vol. 9). Springer Science \& Business Media 284 pp.

Grinsted L, Pruitt JN, Settepani V, Bilde T (2013) Individual personalities shape task differentiation in a social spider. Proc Royal Soc Lond B 280:20131407 10.1098/rspb.2013.1407

Gordon DM (1991) Behavioral flexibility and the foraging ecology of seed-eating ants. Am Nat 138:379-411. 10.1086/285223

Gordon DM (2013) The rewards of restraint in the collective regulation of foraging by harvester ant colonies. Nature 498:91-93. 10.1038/nature12137 [PubMed: 23676676]

Harwood G, Avilés L (2018) The shortfall of sociality: group-living affects hunting performance of individual social spiders. Behav Ecol 29:1487-1493. 10.1093/beheco/ary099

Henschel JR, Schneider J, Meikle T (1996) Does group-living or aggregation of spiders of the genus Stegodyphus affect parasitism by pompilid wasps? Bull Br Arachnol Soc 10:138-140

Henschel JR (1998) Predation on social and solitary individuals of the spider Stegodyphus dumicola (Araneae, Eresidae). J Arachnol:61-69

Hoffman CR, Avilés L (2017) Rain, predators, and spider sociality: a manipulative experiment. Behav Ecol 28:589-596. 10.1093/beheco/arx010

Jandt JM, Bengston S, Pinter-Wollman N, Pruitt JN, Raine NE, Dornhaus A, Sih A (2014) Behavioural syndromes and social insects: personality at multiple levels. Biol Rev 89:48-67. 10.1111/ brv.12042 [PubMed: 23672739]

Janzen DH, Schoener TW (1968) Differences in insect abundance and diversity between wetter and drier sites during a tropical dry season. Ecology 49:96-110. 10.2307/1933565 
Jolles JW, Laskowski KL, Boogert NJ, Manica A (2018) Repeatable group differences in the collective behaviour of stickleback shoals across ecological contexts. Proc Royal Soc Lond B 285:20172629 10.1098/rspb.2017.2629

Kamath A, Primavera SD, Wright CM, Doering GN, Sheehy KA, Pinter-Wollman N, Pruitt JN (2018a) Collective behavior and colony persistence of social spiders depends on their physical environment. Behav Ecol 30:39-47. 10.1093/beheco/ary158 [PubMed: 30846891]

Kamath A, Pruitt JN, Brooks AJ, Ladd MC, Cook DT, Gallagher JP et al. (2018b) Potential feedback between coral presence and farmerfish collective behavior promotes coral recovery. Oikos 10.1111/oik.05854

Kaspari M, Alonso L, O’Donnellkwd S (2000) Three energy variables predict ant abundance at a geographical scale. Proc Royal Soc Lond B 267:485-489. 10.1098/rspb.2000.1026

Keiser CN, Hammer TJ, Pruitt JN (2019) Social spider webs harbour largely consistent bacterial communities across broad spatial scales. Biol Lett 15:20190436 10.1098/rsbl.2019.0436 [PubMed: 31551063]

Keiser CN, Pinter-Wollman N, Ziemba MJ, Kothamasu KS, Pruitt JN (2018) The primary case is not enough: variation among individuals, groups and social networks modify bacterial transmission dynamics. J Animal Ecol 87:369-378. 10.1111/1365-2656.12729

Keiser CN, Pruitt JN (2014) Personality composition is more important than group size in determining collective foraging behaviour in the wild. Proc Royal Soc Lond B 281:20141424 10.1098/ rspb.2014.1424

Keiser CN, Wright CM, Pruitt JN (2015) Warring arthropod societies: social spider colonies can delay annihilation by predatory ants via reduced apparency and increased group size. Behav Process 119: 14-21. 10.1016/j.beproc.2015.07.005

Krause J, Ruxton GD (2002) Living in groups. Oxford University Press

Laskowski KL, Montiglio PO, Pruitt JN (2016) Individual and group performance suffers from social niche disruption. Am Nat 187: 776-785. 10.1086/686220 [PubMed: 27172596]

Lichtenstein JLL, Fisher DN, McEwen BL et al. (2019) Collective aggressiveness limits colony persistence in high- but not low-elevation sites at Amazonian social spiders. J Evol Biol 00:1-6. 10.1111/jeb.13532

Lieth H (1973) Primary production: terrestrial ecosystems. Hum Ecol 1: 303-332. 10.1007/ BF01536729

Loveridge JP (1968) The control of water loss in Locusta Migratoria Migratorioides R. \& F: I. Cuticular water loss. J Exp Biol 49:1-13

Lubin Y, Bilde T (2007) The evolution of sociality in spiders. Adv Stud Behav 37:83-145. 10.1016/ S0065-3454(07)37003-4

Majer M, Holm C, Lubin Y, Bilde T (2018) Cooperative foraging expands dietary niche but does not offset intra-group competition for resources in social spiders. Sci Rep 8:11828 [PubMed: 30087391]

Modlmeier AP, Laskowski KL, DeMarco AE, Coleman A, Zhao K, Brittingham HA et al. (2014) Persistent social interactions beget more pronounced personalities in a desert-dwelling social spider. Biol Lett 10:20140419 10.1098/rsbl.2014.0419 [PubMed: 25165452]

Pinter-Wollman N, Gordon DM, Holmes S (2012) Nest site and weather affect the personality of harvester ant colonies. Behav Ecol 23: 1022-1029. 10.1093/beheco/ars066 [PubMed: 22936841]

Pinter-Wollman N, Mi B, Pruitt JN (2017) Replacing bold individuals has a smaller impact on group performance than replacing shy individuals. Behav Ecol 28:883-889. 10.1093/beheco/arx054

Pruitt JN (2012) Behavioural traits of colony founders affect the life history of their colonies. Ecol Lett 15:1026-1032. 10.1111/j.1461-0248.2012.01825.x [PubMed: 22731959]

Pruitt JN, Goodnight CJ (2014) Site-specific group selection drives locally adapted group compositions. Nature 514:359-362. 10.1038/nature13811 [PubMed: 25274310]

Pruitt JN, Oufiero CE, Avilés L, \& Riechert SE (2012). Iterative evolution of increased behavioral variation characterizes the transition to sociality in spiders and proves advantageous. Am Nat 180: 496-510 10.1086/667576 [PubMed: 22976012] 
Pruitt JN, Wright CM, Lichtenstein JLL, Chism GT, McEwen BL, Kamath A (2018) Selection for collective aggressiveness favors social susceptibility in social spiders. Curr Biol 28: 100-105. 10.1016/j.cub.2017.11.038 [PubMed: 29276129]

Purcell J (2011) Geographic patterns in the distribution of social systems in terrestrial arthropods. Biol Rev 86:475-491. 10.1111/j.1469-185X.2010.00156.x [PubMed: 20840372]

Purcell J, Avilés L (2008) Gradients of precipitation and ant abundance may contribute to the altitudinal range limit of subsocial spiders: insights from a transplant experiment. Proc Royal Soc Lond B 275:2617-2625. 10.1098/rspb.2008.0582

Rayor LS (1996) Attack strategies of predatory wasps (Hymenoptera: Pompilidae; Sphecidae) on colonial orb web-building spiders (Araneidae: Metepeira incrassata). J Kans Entomol Soc:67-75

Rayor LS, Uetz GW (1990) Trade-offs in foraging success and predation risk with spatial position in colonial spiders. Behav Ecol Sociobiol 27:77-85. 10.1007/BF00168449

Riechert SE (1985) Why do some spiders cooperate? Agelena consociata, a case study. Flor Entomol:105-116. 10.2307/3494333

Riechert SE (1993) Investigation of potential gene flow limitation of behavioral adaptation in an aridlands spider. Behav Ecol Sociobiol 32:355-363. 10.1007/BF00183792

Rypstra AL, Tirey RS (1991) Prey size, prey perishability and group foraging in a social spider. Oecologia 86(1):25-30. 10.1007/BF00317384 [PubMed: 28313153]

Scharf I, Modlmeier AP, Fries S, Tirard C, Foitzik S (2012) Characterizing the collective personality of ant societies: aggressive colonies do not abandon their home. PLoS One 7:e33314 10.1371/ journal.pone.0033314 [PubMed: 22457751]

Settepani V, Schou MF, Greve M, Grinsted L, Bechsgaard J, Bilde T (2017) Evolution of sociality in spiders leads to depleted genomic diversity at both population and species levels. Mol Ecol 26:4197-4210. 10.1111/mec.14196 [PubMed: 28570031]

Siepielski AM, DiBattista JD, Carlson SM (2009) It's about time: the temporal dynamics of phenotypic selection in the wild. Ecol Lett 12:1261-1276. 10.1111/j.1461-0248.2009.01381.x [PubMed: 19740111]

Siepielski AM, Gotanda KM, Morrissey MB, Diamond SE, DiBattista JD, Carlson SM (2013) The spatial patterns of directional phenotypic selection. Ecol Lett 16:1382-1392. 10.1111/ele.12174 [PubMed: 24028500]

Siepielski AM, Morrissey MB, Buoro M, Carlson SM, Caruso CM, Clegg SM et al. (2017) Precipitation drives global variation in natural selection. Science 355:959-962. 10.1126/ science.aag2773 [PubMed: 28254943]

Traniello JF, Fujita MS, Bowen RV (1984) Ant foraging behavior: ambient temperature influences prey selection. Behav Ecol Sociobiol 15: 65-68. 10.1007/BF00310217

Whitehouse MEA, Jackson RR (1998) Predatory behaviour and parental care in Argyrodes flavipes, a social spider from Queensland. J Zool 244:95-105. 10.1111/j.1469-7998.1998.tb00011.x

Whitehouse ME, Lubin Y (2005) The functions of societies and the evolution of group living: spider societies as a test case. Biol Rev 80:347-361. 10.1017/S1464793104006694 [PubMed: 16094803]

Wray MK, Mattila HR, Seeley TD (2011) Collective personalities in honeybee colonies are linked to colony fitness. Anim Behav 81: 559-568. 10.1016/j.anbehav.2010.11.027

Wright CM, Keiser CN, Pruitt JN (2016) Colony personality composition alters colony-level plasticity and magnitude of defensive behaviour in a social spider. Anim Behav 115:175-183. 10.1016/ j.anbehav.2016.03.002

Wright CM, Lichtenstein JL, Montgomery GA, Luscuskie LP, Pinter-Wollman N, Pruitt JN (2017) Exposure to predators reduces collective foraging aggressiveness and eliminates its relationship with colony personality composition. Behav Ecol Sociobiol 71:126-111. 10.1007/ s00265-017-2356-7 [PubMed: 29606787]

Wrona FJ, Dixon RJ (1991) Group size and predation risk: a field analysis of encounter and dilution effects. Am Nat 137:186-201. 10.1086/285153

Yip EC, Powers KS, Avilés L (2008) Cooperative capture of large prey solves scaling challenge faced by spider societies. Proc Royal Soc Lond B 105:11818-11822. 10.1073/pnas.0710603105

Yip EC, Rayor LS (2011) Do social spiders cooperate in predator defense and foraging without a web? Behav Ecol Sociobiol 65:1935-1947. 10.1007/s00265-011-1203-5 


\section{Significance statement}

Many social animals are susceptible to group extinction events. Identifying the factors that precipitate these events can help us to understand how societies function and evolve. We used a social spider model to evaluate whether the drivers of group extinction events may vary with habitat type. We found that ant attacks were more commonly associated with colony demise at arid sites, whereas fungal outbreaks were associated with collapse in wetter environments. If maintained temporally, these contrasting selection pressures could facilitate the evolution of local adaptation in individual- and colony-level phenotypes and aid in the maintenance of intraspecific trait diversity. 


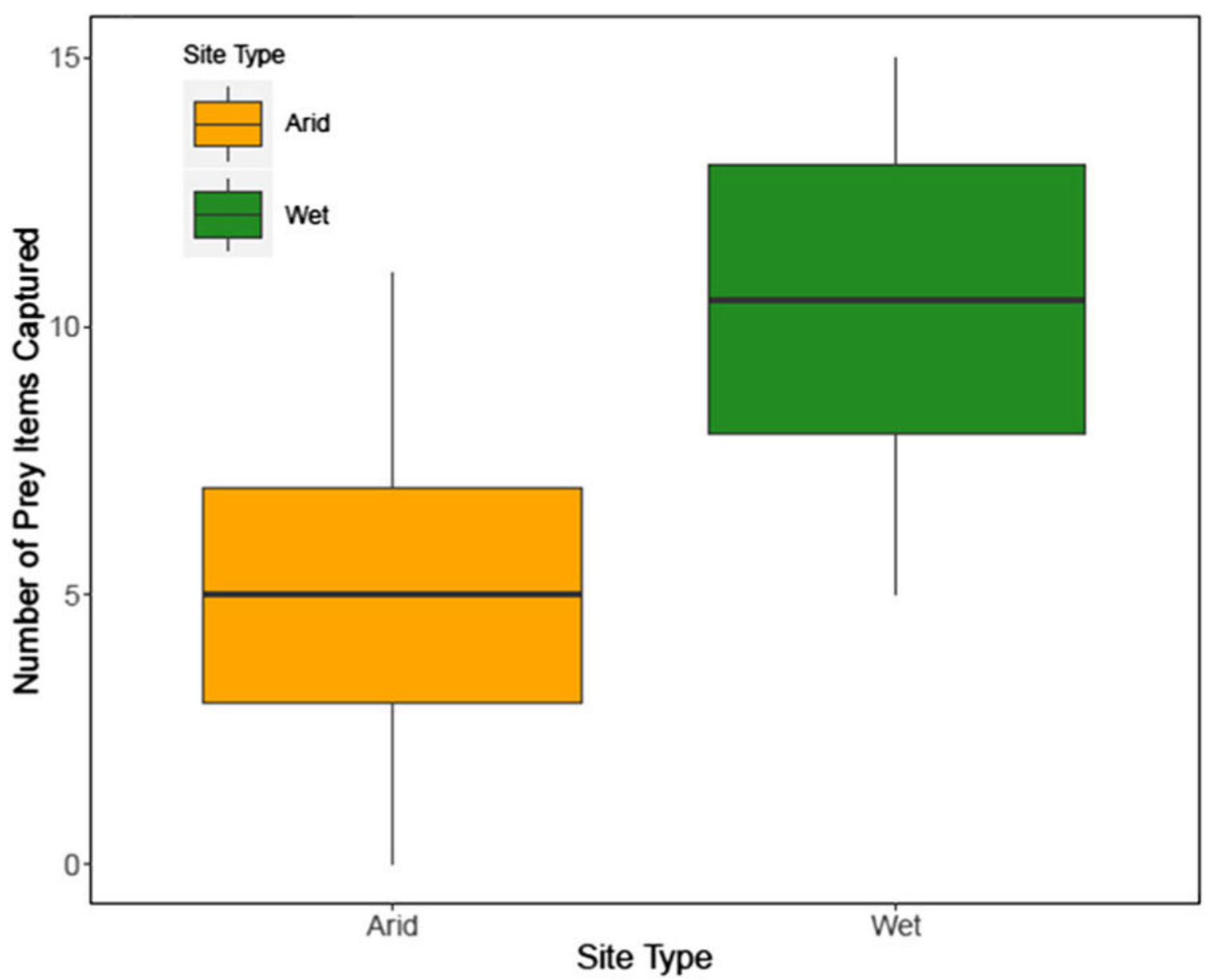

Fig. 1.

Number of prey items captured differs between site types. Number of prey items recovered from webs of colonies that survived the full duration of the study and did not display signs of ant attack in arid sites (orange) and wet sites (green). Boxes indicate the lower and upper quartiles; horizontal lines within boxes indicate the median, and whiskers extend to the 1.5 interquartile range from the box 


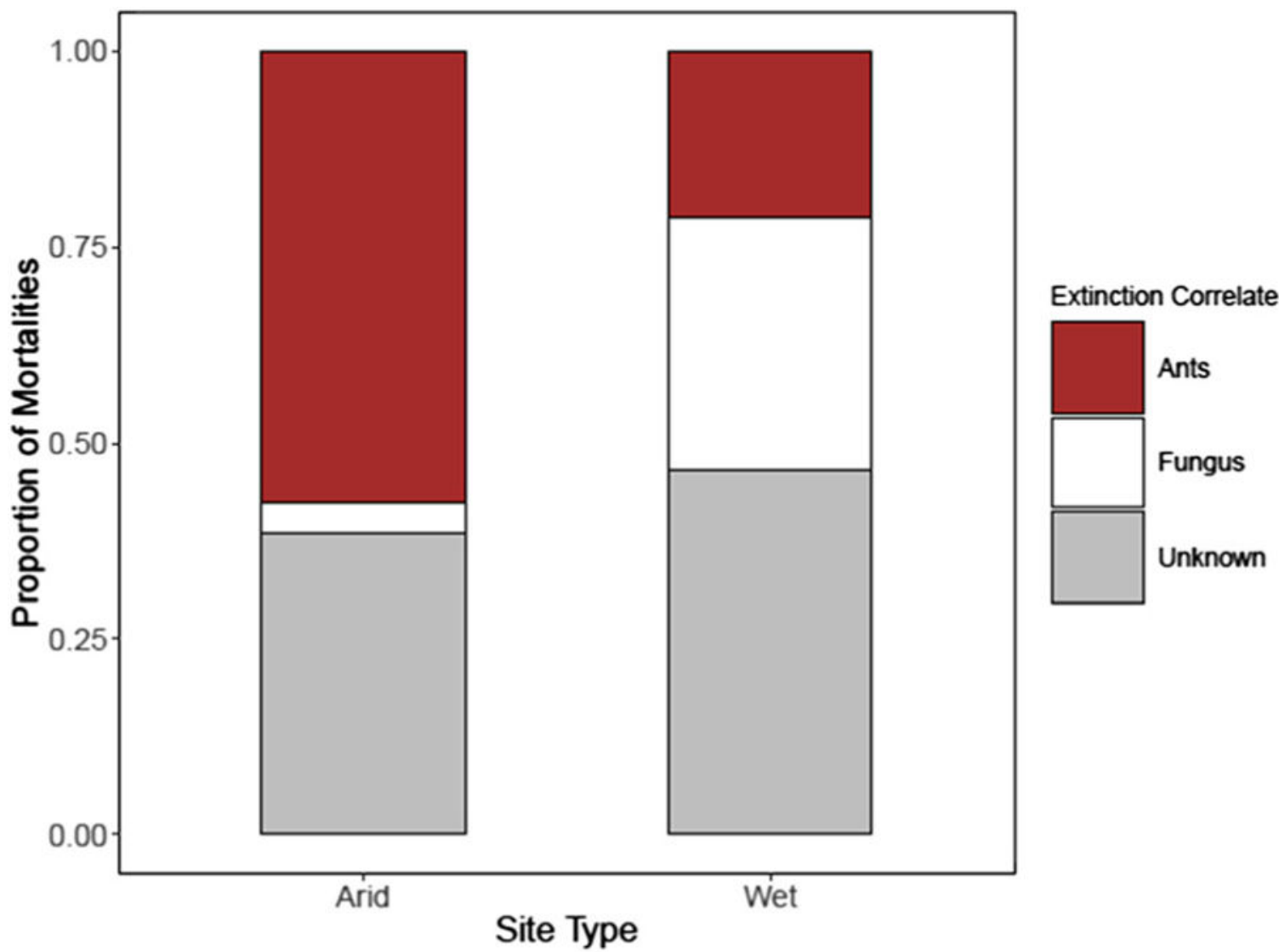

Fig. 2.

Correlates of extinction vary by site type. Proportion of total colony extinctions associated with ant attacks (red), fungal outbreaks (white), and unknown causes (gray) at arid (left) and wet (right) sites. Colonies containing Anoplolepis spp. carcasses were noted to be attacked by predatory ants, while colonies containing puffs of white fungus riddled through the nest were recorded as associated with fungal outbreaks 


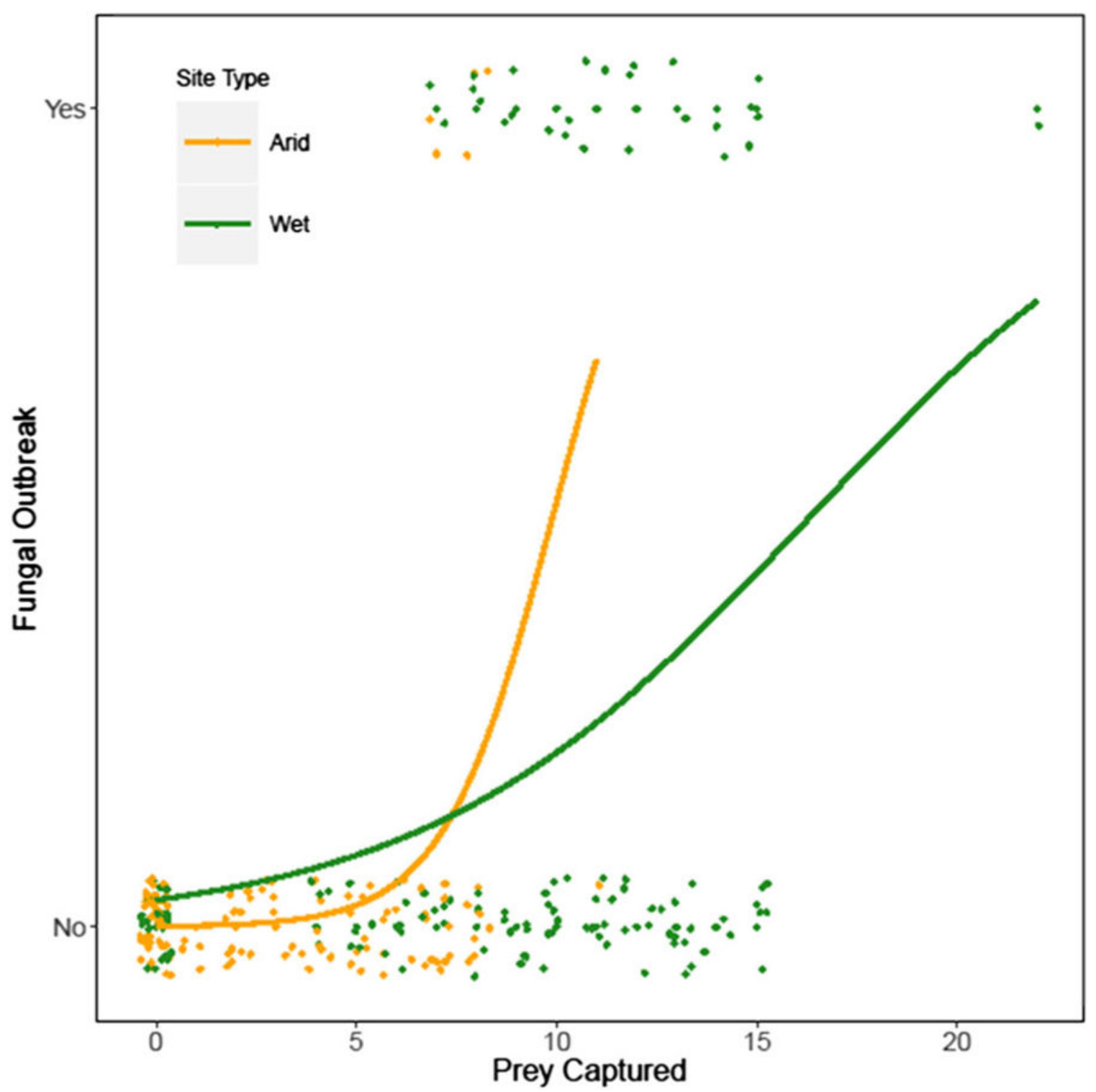

Fig. 3.

Incidence of fungal outbreak versus prey capture rate. Relationship between (binary) occurrence of fungal outbreak and prey capture rate at arid (orange) and wet (green) sites. Points are jittered along the $y$ axis to improve visibility. A logistic regression of predicted values for fungal outbreak as a function of prey capture is displayed by site type (arid: orange, wet: green). No significant interaction between site type and prey capture was detected; colonies at both site types experience comparable increasing risk of fungal outbreak with increasing prey capture 


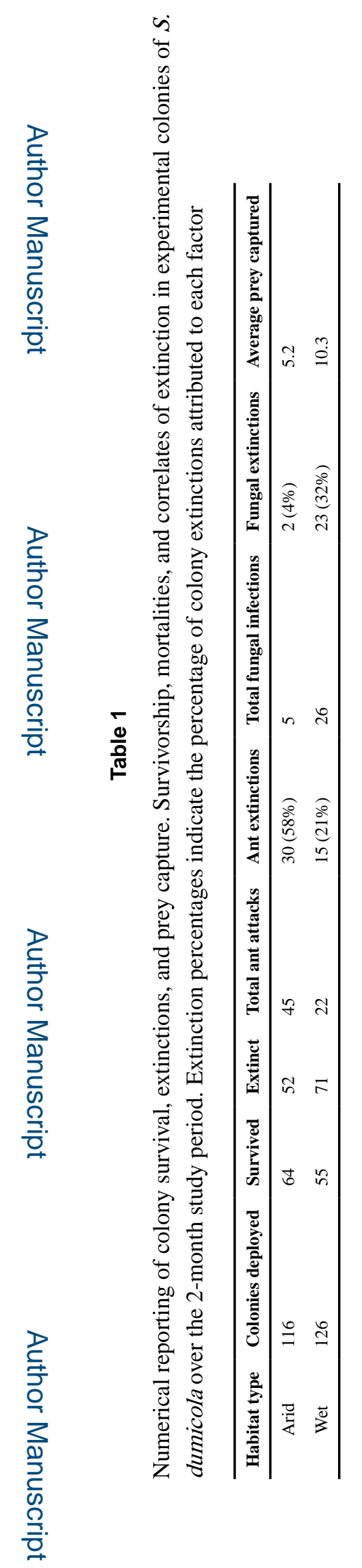

Behav Ecol Sociobiol. Author manuscript; available in PMC 2020 May 19 